\title{
Report of the 15th International Scientific Conference on Transformation Processes in Sport "Sports Performance"
}

\author{
Miomir Maros ${ }^{1}$ \\ 'University of Montenegro, Faculty for Sport and Physical Education, Niksic, Montenegro
}

\begin{abstract}
The article discusses the highlights of the 15th International Scientific Conference on Transformation Processes in Sport "Sports Performance", which was held in Budva, Montenegro. The event comprised oral and poster sessions. At the opening of the conference they spoke Rector of the University of Montenegro Danilo Nikolic, Sports Minister Nikola Janovic, Stevo Popovic, Dean of the Faculty for Sport and Physical Education at University of Montenegro. The prestigious conference "Transformational processes in sport - sports achievements" gathered 350 participants from 24 countries of the world, from four continents.
\end{abstract}

Key words: Sports - Congresses, Conferences \& Conventions, School Sports - Congresses

Prestižna Međunarodna naučna konferencija „Transformacioni procesi u sportu - sportska dostignuća“, koja je okupila oko 350 učesnika iz 24 zemlje, sa četiri kontinenta, održana je u Budvi, od 12. do 15. aprila 2018. godine.

Konferencija koja ima 15 godina tradicije i razmatra aktuelne teme i novine iz svih oblasti sportskih nauka i sportske medicine, uz multidisciplinarni pristup, i sa aspekta drugih nauka, od početka ima podršku Univerziteta Crne Gore, podsjetio je na otvaranju Rektor Univerziteta prof. dr Danilo Nikolić. Nikolić je ustvrdio da je ta podrška doprinijela da konferencija postane jedinstveni događaj u regionu, na domaćem i međunarodnom planu, i jedna od najznačajnijih i najprestižnijih manifestacija u oblasti sporta i sportske medicine. Rektor Nikolić je iskazao posebno zadovoljstvo zbog toga što Crnogorska sportska akademija na sesijama konferencije pruža priliku za promociju mladih najboljih istraživača kroz ustanovljene nagrade, što može biti podsticaj za dalji naučno-istraživački rad mladih talenata“, istakao je rektor Nikolić.

Ministar sporta u Vladi Crne Gore, proslavljeni vaterpolo reprezentativac Nikola Janović istakao je da se značaj ove konferencije ogleda u tome što pruža mogućnosti za podsticanje razvoja sportske nauke u Crnoj Gori. „Vjerujem da će Konferencija biti dobra prilika i prostor za razmjenu naprednih iskustava i prakse koja će doprinijeti boljoj promociji sporta, zdravlja i važnosti edukacije u različitim modelima brige o budućim naraštajima“, kazao je ministar Janović, podsjetivši da Ministarstvo sporta realizuje aktivnosti na unapređenju kvaliteta života građana, a pogotovo mladih, kroz bavljenje sportom, koji je ključni element za psiho-fizički i socijalni razvoj ličnosti, a u cilju stvaranja zdrave nacije.

Dekan Fakulteta za sport i fizičko vaspitanje doc. dr Stevo Popović je naglasio da je fokus konferencije na studentima. „Ugostili smo 100 studenata magistarskih i doktorskih studija i pripremili za njih predavanja profesora sa Univerziteta u Nici Sofija Antipolis, kroz Erasmus + program“, kazao je dekan Popović. Predavači konferencije kojih je devet po pozivu, vodeći su naučni istraživači i eksperti na polju sportskih nauka, a na konferenciji su organizovane dvije radionice i panel diskusije. „Imali smo viziju prije pet godina da naša konferencija od regionalne izraste $u$ internacionalnu, i danas, u petom izdanju organizovanom prema modernim stadardima i naučnim procedurama, mogu slobodno da kažem da je ovo najprepoznatljivija konferencija na polju sportskih nauka na našm kontinentu i šire“, zaključio je doc.dr Stevo Popović.

Correspondence:

Montenegro M. Maros

Gport University of Montenegro, Faculty for Sport and Physical Education, Narodne omladine bb, 81400 Niksic, Montenegro E-Mail:miomirm@ac.me 


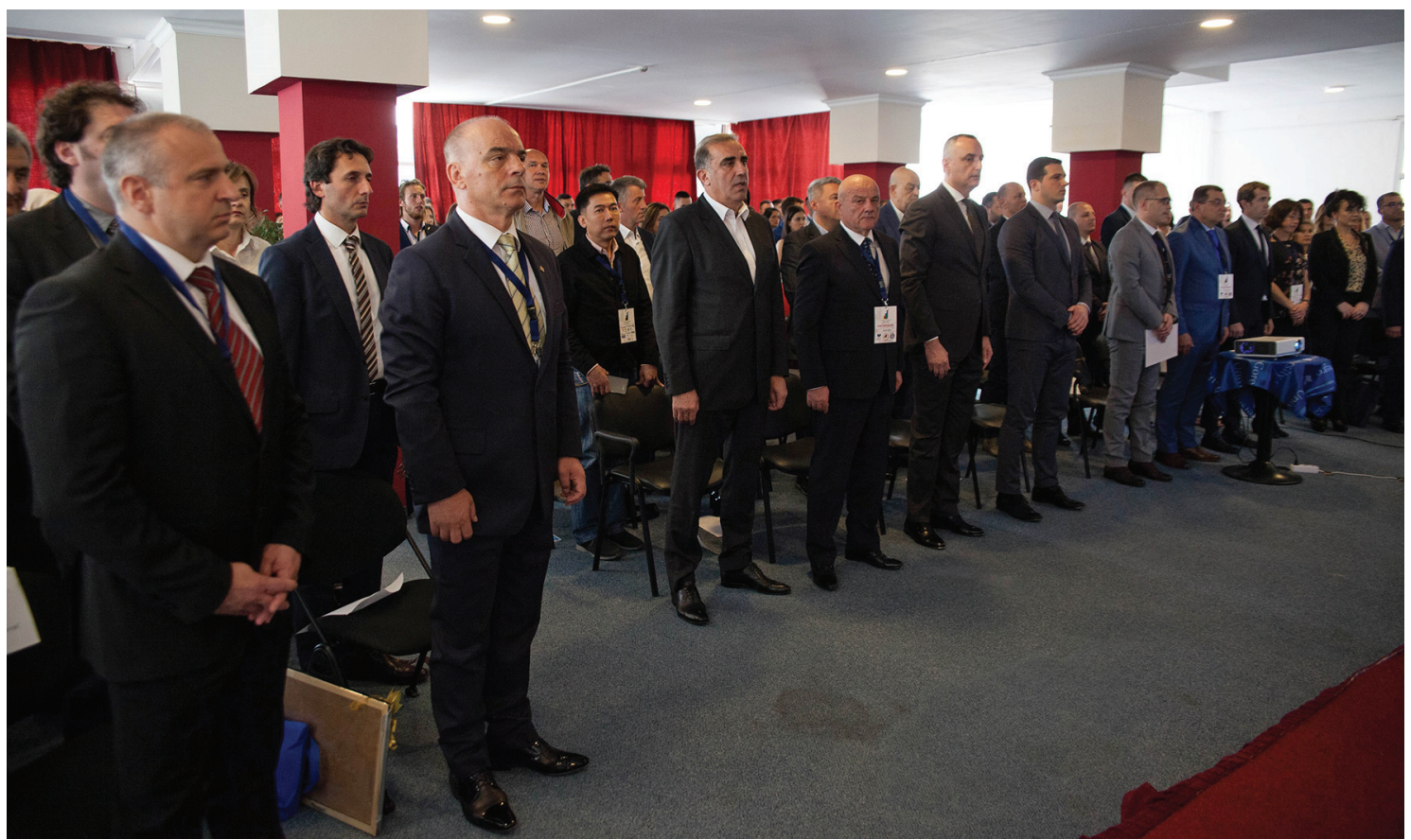

Picture 1. Svečano otvaranje konferencije

Teme predstavljene na konferenciji su iz antropologije, biomehanike, sportskog treninga, motorike, adaptivnog fizičkog vježbanja, biohemije, zdravlja i fitnesa, molekularne biologije, neuromuskularne fiziologije, nutricionizma, fiziologije, fizioterapije, rehabilitacije, sportske medicine, traumatologije, olimpizma, informatičkih nauka, ekonomije, istorije, filozofije i etike, fizičkog vaspitanja i pedagogije, sociologije, sportskog menadžmenta, statistike u sportu i sportskog turizma.

Konferenciju organizuje Crnogorska sportska akademija u saradnji sa Univerzitetom Crne Gore, odnosno Fakultetom za sport i fizičko vaspitanje i Ekonomskim fakultetom, Crnogorskim olimpijskim komitetom, Vladom Crne Gore, kao i međunarodnim partnerskim institucijama (Univerzitet u Novom Sadu iz Srbije, Univerzitet u Sarajevu iz Bosne i Hercegovine,
Sofia Antipolis Univerzitet u Nici iz Francuske, Univerzitet u Koimbri iz Portugala, Univerzitet Sporta u Tirani iz Albanije, Univerzitet u Primorskoj iz Slovenije, Azijska asocijacija za vježbanje i sportske nauke iz Irana, i Evropski koledž za sportske nauke iz Njemačke).

Za poseban doprinos međunarodnoj naučnoj konferenciji, predsjedavajući konferencije prof. dr Duško Bjelica uručio je četiri zlatne plakete. Plakete su primili ministar Janović, u ime Vlade Crne Gore, Rektor Nikolić u ime Univerziteta, predsjednik Dušan Simonović u ime Crnogorskog olimpijskom komiteta i prof. dr Zoran Milošević, član pokrajinske Vlade Vojvodine $\mathrm{u}$ ime Pokrajinskog sekretarijata za visoko obrazovanje i naučno istraživanje - Vlade Vojvodine

Profesor dr Boštjan Šimunić, sa Instituta za kineziološka

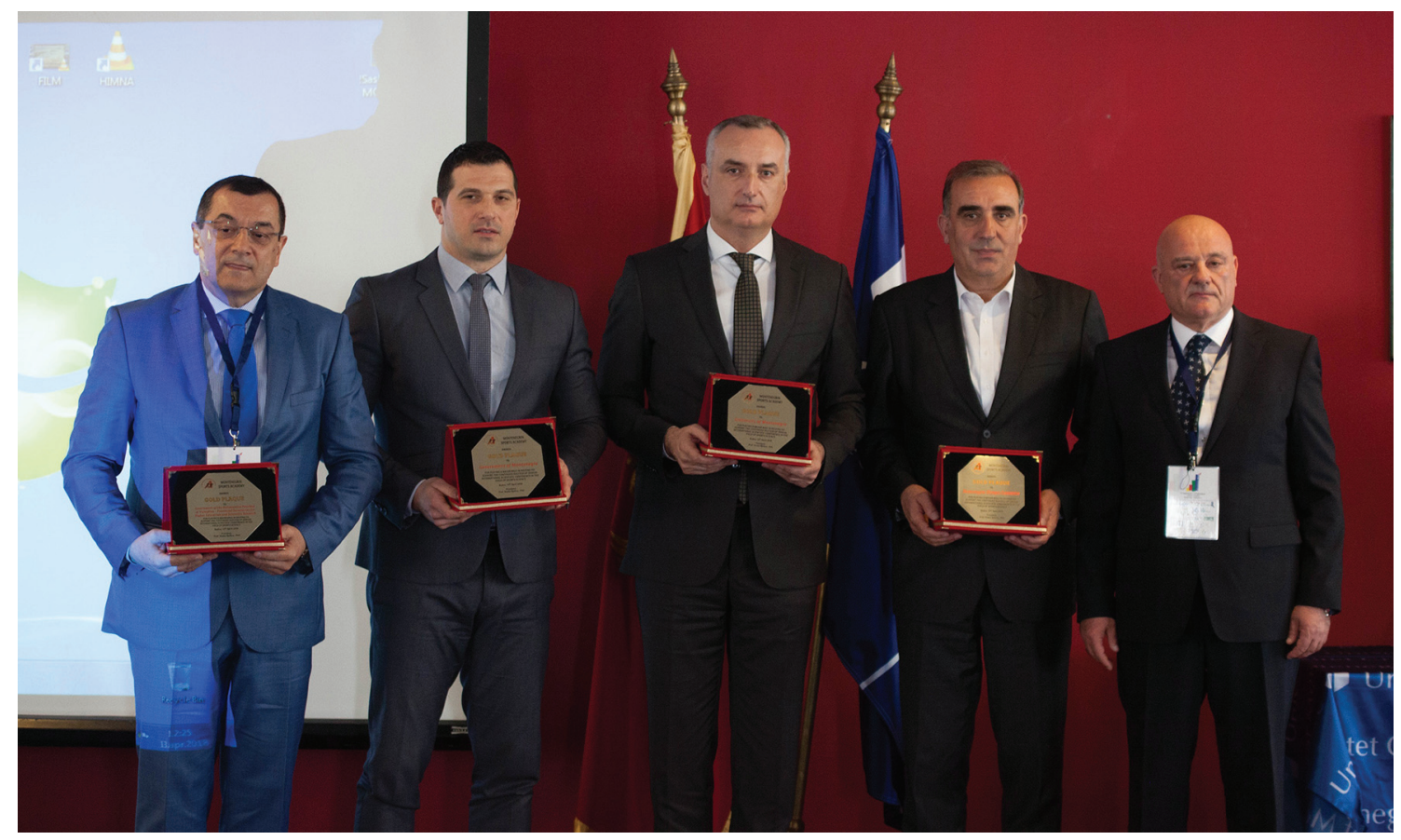

Picture 2. Dobitnici zlatnih plaketa 
istraživanja Kopar (Slovenija) smatra da su konferencije, kao što je 15. Međunarodna naučna konferencija „Transformacioni procesi u sportu - sportska dostignuća" u Budvi, uvijek dobrodošle, tu se srijeću znanja, različiti pogledi i diskusije i to je ono najbitnije što studenti moraju tokom i poslije diplomskih studija upoznati i biti dio toga. „Na njima je da predstave svoje radove, da dobiju od nas konkretne komentare, što je loše, a što dobro napravljeno itd. To je sigurno vrlo bitno za njihov razvoj. Bitno je i za naše napredovanje, jer kad na konferenciji mi predstavljamo svoje najnovije radove koje smo objavili ili želimo objaviti i nemamo objašnjenja recimo za neke pojmove koje smo ustanovili, možemo ovdje na podijumu pitati ostale šta oni misle, i onda dolazi do diskusija i dobrih ideja“, zaključio je prof.dr Boštjan Šimunić, inače bivši reprezentativac Slovenije u atletici.
Prof. dr Catalina Casaru sa Georgia Southwestern State University u SAD-u, smatra da je Međunarodna naučna konferencija "Transformacioni procesi u sportu-sportska dostignuća" ove godine bila izvanredna. "Zaista sam uživala u boravku ovdje i zahvaljujem naučnom i organizacionom odboru na pozivu. Član sam odbora crnogorskog časopisa za sportske nauke i medicinu Montenegrin Journal of Sports Science and Medicine (MJSSM) već dvije godine, kao recenzent i bilo je lijepo upoznati sve ove ljude. Mislim da nas je to više zbližilo i vjerovatno ćemo u budućnosti imati neke ciljeve za časopis, da ga učinimo boljim, pristupačnijim i povećamo broj dobrih članaka koji se objavljuju u časopisu", zaključuje prof. dr Catalina Casaru, inače bivša olimpijska reprezentativka Rumunije u plivanju.

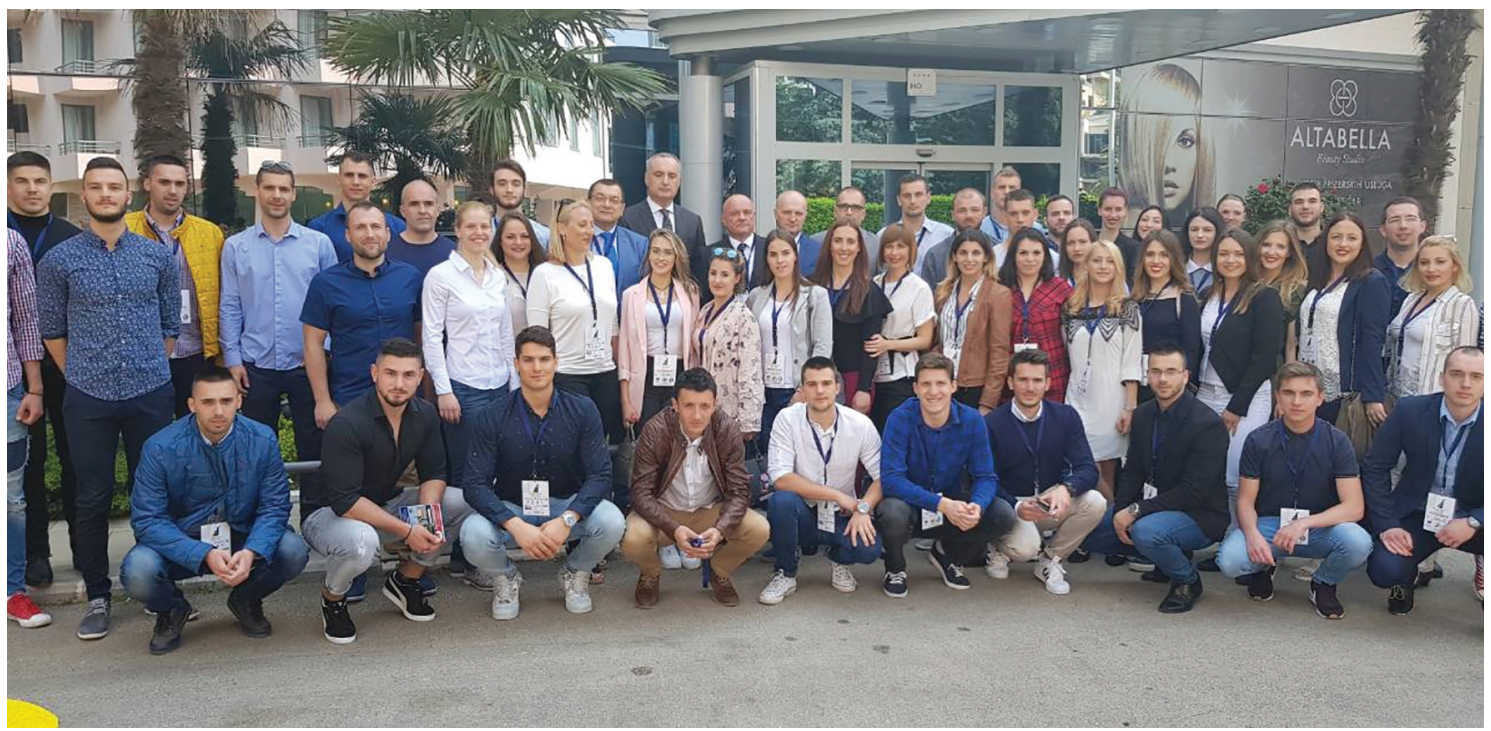

Picture 3. Rukovodstvo Univerziteta Crne Gore sa studentima - učesnicima konferencije

Na ceremoniji zatvaranja XV Međunarodne naučne konferencije „Transformacioni procesi u sportu - sportska dostignuća“, uručene su nagrade i plakete najboljima. Nagrada za najbolju ženu naučnika pripala je dr Lauri Schuft, sa Fakulteta za sportske nauke sa Univerziteta u Nici - Sofia Antipolis. Za najboljeg mladog naučnika je promovisana dr Vedrana Sember sa Fakulteta za sport, Univerziteta u Ljubljani. Specijalno priznanje u ime Olimpijskog komiteta Bosne i Hercegovine, profesoru dr Dušku Bjelici, uručio je prof.dr Izet Rađo. Profesoru dr Goranu Sporišu, sa Kineziološkog fakulteta Sveučilišta u Zagrebu, uručena je plaketa za lični doprinos za podsticanje nauke na internacionalnom nivou.

Međunarodna naučna konferencija „Transformacioni procesi u sportu", 16. po redu, prema najavama organizatora iz Crnogorske sportske akademije, biće održana u Dubrovniku, u Hrvatskoj, polovinom aprila 2019. godine.

\section{Acknowledgements}

There are no acknowledgements.

\section{Conflict of Interest}

The authors declare that there are no conflict of interest.

Received: 25 April 2018| Accepted: 05 June 2018| Published: 13 July 2018

\section{References}

Bjelica, D., Popovic, S., \& Akpinar, S. (2014). Book of Abstract of the 11th International Scientific Conference on Transformation Process in Sport "Sport Performance". Podgorica: Montenegrin Sports Academy.

Bjelica, D., Popovic, S., \& Akpinar, S. (2015). Book of Abstracts of the 12th International Scientific Conference on Transformation Process in Sport "Sport Performance". Podgorica: Montenegrin Sports Academy.

Bjelica, D., Popovic, S., \& Akpinar, S. (2016). Book of Abstracts of the 13th International Scientific Conference on Transformation Process in Sport "Sport Performance". Podgorica: Montenegrin Sports Academy.

Bjelica, D., Popovic, S., \& Akpinar, S. (2017). Book of Abstracts of the 14th International Scientific Conference on Transformation Process in Sport "Sport Performance". Podgorica: Montenegrin Sports Academy.

Bjelica, D., Popovic, S., \& Akpinar, S. (2018). Book of Abstracts of the 15th International Scientific Conference on Transformation Process in Sport "Sport Performance". Podgorica: Montenegrin Sports Academy. 